\title{
Diferentes Abordagens dos Fenômenos Subjetivos na Obra de B. F. Skinner
}

\author{
Henrique Mesquita Pompermaier * \\ Universidade Federal de São Carlos, São Carlos, Brasil \\ Camila Muchon de Melo \\ Universidade Estadual de Londrina, Londrina, Brasil \\ Naiene dos Santos Pimentel \\ Universidade Federal de São Carlos, São Carlos, Brasil
}

\begin{abstract}
RESUMO
Como a análise do comportamento aborda os fenômenos subjetivos? Seria a teoria de eventos privados a única maneira? Guiado por essas questões, o presente trabalho busca apresentar a abordagem dos fenômenos subjetivos na obra de B. F. Skinner, indicando não apenas a teoria de eventos privados, mas também a possibilidade de abordagens alternativas a essa temática, sem referência à privacidade, por exemplo, por meio da magnitude das ações envolvidas nos fenômenos, níveis (aberto e encoberto) do comportamento e conceitos disposicionais. Indica-se ainda uma significativa diferença de ênfase na teoria de eventos privados ao longo da obra skinneriana. Por fim, conduz-se uma discussão sobre o papel da teoria de eventos privados na análise do comportamento para a abordagem dos fenômenos subjetivos.
\end{abstract}

Palavras-chave: fenômenos subjetivos; B. F. Skinner; teoria de eventos privados; explicações disposicionais.

\begin{abstract}
Different approaches to subjective phenomena on B. F. Skinner's work

How do behavior analysis approaches subjective phenomena? Would the private events theory be the only way to do it? Guided by these questions, this paper aims to present the approach to subjective phenomena in B. F Skinner's work, indicating not only the theory of private events but also the possibilities of alternative approaches to this subject, with no reference to privacy, for example, through the magnitude of actions involved in the phenomena, levels of behavior and dispositional concepts. We also indicate a significant difference of emphasis on the private events theory throughout Skinner's work. Finally, we discuss the role of the private events theory in the behavior analysis' approach to subjective phenomena.

Keywords: subjective phenomena; B. F. Skinner; theory of private events; dispositional accounts.
\end{abstract}

A ciência, à época dos primeiros behavioristas era pautada na experimentação, na objetividade, na verdade por consenso entre observadores e na possibilidade de observação pura do mundo (Carrara, 2005; Chiesa, 1994; Marx \& Hillix, 1976). Nesse sentido, o comportamento foi eleito como objeto de estudo pelos behavioristas justamente por atender às demandas de um objeto passível de mensuração, quantificação e observação direta, ou seja, passível de uma investigação verdadeiramente científica (nos moldes do que convencionalmente chama-se de ciência moderna) (Abib, 1997; Skinner, 1987).

Dessa maneira, as pretensões dos primeiros behavioristas, de status de ciência natural para a Psicologia, pareciam culminar em uma negação (posição watsoniana) ou desprezo (posição behaviorista meto-

* Endereço para correspondência: Henrique Mesquita Pompermaier - henriquepompermaier@gmail.com 
dológica) do estudo de fenômenos mentais e subjetivos, ao menos na forma como eram tratados pelas demais tradições que propunham uma ciência da consciência (Lopes, 2006; Strapasson \& Carrara, 2008). Contudo, abordar questões referentes a eventos não observáveis diretamente, como pensamentos, sentimentos e estados motivacionais, continuava a ser uma demanda premente apresentada ao que se entendia por "campo psicológico". Como apontado por alguns autores (e.g., Carrara, 2005; Lopes, 2006; Skinner, 1974/1976), essa implicação foi um dos principais motes para críticas ao Behaviorismo'. Uma proposta de psicologia que desconsiderasse fenômenos tão presentes e importantes na vida, como afirma Lopes (2006, p. 13), seria "no mínimo, contraintuitiva".

B. F. Skinner (1945/1961; 1953/1965; 1968; 1971; 1974/1976; 1989/1991) desenvolveu uma extensa obra na qual procura elaborar um projeto de compreensão dos fenômenos psicológicos a partir de uma abordagem também científica dos mesmos, porém com distinções importantes em relação às escolas behavioristas anteriores. Propôs, para tanto, o desvio do foco no método empregado em direção à explicação dos fenômenos psicológicos. Buscava, com essa mudança, a construção de conceitos que possibilitassem explicações pautadas no mundo natural, conceitualmente econômicas e úteis (Baum, 1994). A partir disso, Skinner rotulou a visão behaviorista anterior como "behaviorismo metodológico", e denominou sua posição como "behaviorismo radical" (Skinner, 1945/ 1961).

O behaviorismo radical se contrapõe tanto às correntes mentalistas, que buscam a explicação para os fenômenos psicológicos em eventos ou construtos de alguma outra natureza, como ao behaviorismo metodológico (Carvalho Neto, 2002; Sério, 2005). Tal distanciamento em relação às duas tradições mostra-se, sobretudo, no tratamento dado à temática dos fenômenos mentais e subjetivos, tradicionalmente marcado pelas dicotomias público-privado e físicomental (Tourinho, 2009). Nas palavras de Skinner (1945/ 1961):

A distinção entre público e privado não é, de modo algum, a mesma que há entre físico e mental. É por isso que o behaviorismo metodológico (que adota a primeira alternativa) é muito diferente do behavio- rismo radical (que elimina o último termo da segunda alternativa). O resultado é que, enquanto o behaviorista radical pode, em alguns casos, considerar os eventos privados (inferencialmente, talvez, mas mesmo assim de maneira significativa), o operacionista metodológico tem se colocado em uma posição na qual não pode fazê-lo. (p. 285)

Entretanto, mesmo com as distinções apontadas, Skinner parece manter, ao menos em suas obras iniciais, um compromisso com a tradição do descritivismo científico $^{2}$ (fortemente presente nas propostas behavioristas anteriores) para explicação, previsão e controle do objeto de investigação de sua ciência do comportamento. Possivelmente isso se deva às discussões entre as correntes psicológicas do início do século $\mathrm{XX}$ e ao compromisso com o desenvolvimento de uma abordagem que fosse reconhecida e legitimada como científica (Abib, 1997) ${ }^{3}$.

Junto a essa pretensão de reconhecimento científico, a proposta skinneriana acabou por herdar também algumas problemáticas da tradição descritivista, como o tema da acessibilidade ao objeto de estudo. A demanda que se colocava era: como abordar questões referentes a fenômenos psicológicos não observáveis diretamente por mais de um observador - como pensamentos, sentimentos e estados motivacionais -, inquestionavelmente essenciais a qualquer proposta de sistema psicológico, sem recorrer a construtos e proposições mentalistas? Ou, ainda, sem identificar abordagens limitantes propostas por outras correntes de pensamento da tradição descritivista, como as do behaviorismo metodológico e watsoniana, ou de metodologia científica questionável, como a Escola Introspeccionista? Skinner parece reconhecer o desafio desta questão em mais de um momento, como na afirmação de que:

A questão é antiga, tendo ocupado a atenção de filósofos e outros por mais de dois mil anos. Nunca foi resolvida satisfatoriamente. [...] Não obstante, o assunto tem importância e deve ser estudado em alguma ocasião. A ciência moderna tem tentado apresentar uma concepção ordenada e integrada da natureza. Alguns de seus maiores expoentes preocuparam-se com as vastas implicações da ciência com respeito à estrutura do universo. Quase sempre o quadro que emerge é dualista. Humildemente o cientista admite que descreve apenas metade do universo, e admite um outro mundo - o mundo da mente ou da cons- 
ciência - no qual se supõe que seja necessário outro tipo de investigação. Este ponto de vista não é inegável, mas é parte da herança cultural, da qual a ciência emergiu. A contribuição que uma ciência do comportamento pode dar, ao sugerir um ponto de vista alternativo, é talvez uma de suas realizações mais importantes. (Skinner, 1953/1965, p.258)

Em acordo com essa indicação, o objetivo do presente trabalho é apresentar algumas possibilidades de abordagem de fenômenos subjetivos na obra de Skinner. $O$ texto inicia-se com algumas considerações sobre a subjetividade no behaviorismo radical, indicando a teoria de eventos privados como resposta comumente adotada, a partir de sua proposição na obra de Skinner (1945/1961). Nesse sentido, apresentam-se os principais aspectos da teoria de eventos privados, como a questão da dificuldade de acesso direto a tais eventos por mais de um observador e as estratégias utilizadas pela comunidade verbal para driblar tal dificuldade ao ensinar repertórios discriminativos e autodescritivos. Em seguida, destaca-se que, mesmo na obra de Skinner (e.g., 1953/1965; 1989/ 1991), encontram-se discussões sobre fenômenos subjetivos sem referência à teoria de eventos privados, por meio de análises com foco na magnitude das ações envolvidas nos fenômenos, níveis do comportamento (aberto e encoberto) e conceitos disposicionais. A partir disso, desenvolve-se a análise de alguns fenômenos subjetivos - emoções, sentimentos, pensamento, consciência e self-considerando a diferença de ênfase na teoria de eventos privados conferida para o tratamento de cada um desses fenômenos, ou ainda, a diferença dessa ênfase no tratamento de um mesmo fenômeno em diferentes momentos da obra skinneriana. Por fim, questiona-se o papel da teoria de eventos privados para a abordagem dos fenômenos subjetivos na obra de Skinner.

\section{SUBJETIVIDADE NO BEHAVIORISMO RADICAL}

Segundo Abib (1997), é possível identificar na obra skinneriana dois momentos, ou duas respostas à possibilidade de construção de investigação e conhecimento científico acerca de questões da subjetividade dos indivíduos, tratadas muitas vezes como questões relativas a "eventos privados": uma negativa e outra positiva. A resposta negativa diz que o método experimental não é adequado para investigar e explicar os eventos privados, e revela uma abordagem epifenomenalista desses eventos, próxima à abordagem do behaviorismo metodológico.

Contudo, segundo Abib (1997), Skinner reconhece que, na medida em que podem ser descritos pelo indivíduo, estados internos como sentimentos, pensamentos, crenças, conhecimentos e propósitos podem ser também determinantes do comportamento: "Como as pessoas se sentem é frequentemente tão importante quanto o que elas fazem" (Skinner, 1989/1991, p.13). Desse modo, encaminhando a resposta positiva, Skinner (1945/ 1961) propõe o abandono da ideia de abordagem direta desses eventos, admitindo que todo conhecimento acerca desses fenômenos seria indireto e inferencial. Para tanto, Skinner faz uso de instrumentos conceituais como a teoria do comportamento verbal, teoria funcional do significado e o próprio conceito de eventos privados (Abib, 1997). Segundo Skinner (1945/1961), o uso do conceito de eventos privados, referente a estímulos e respostas não observáveis publicamente, mais funcionalmente relacionados a estímulos e respostas públicos, permitiria a abordagem científica dos fenômenos subjetivos.

Desde a sua proposição, a teoria de eventos privados de Skinner (1957; 1945/1961; 1953/1965; 1969; 1974/1976) configura-se como o modo mais comum de abordar a temática da subjetividade no behaviorismo radical. Tal teoria teria tamanha importância a ponto de marcar para alguns autores (e.g., Matos, 1995; Moore, 1995; Tourinho, 2004) a distinção entre o behaviorismo radical e os demais behaviorismos. Passemos à exposição dessa teoria.

\section{A TEORIA DE EVENTOS PRIVADOS}

O conceito de eventos privados foi utilizado por Skinner (1945/1961) em seu texto The operational analysis of psychological terms, buscando distinguir estímulos e respostas inacessíveis à observação pública direta daqueles que eram diretamente observados, a partir de considerações acerca de processos de discriminação de estímulos e ensino da descrição destes (comportamento verbal) por uma comunidade. Vejamos o que diz o autor:

O reforçamento da resposta "vermelho", por exemplo, é contingente à presença de um objeto vermelho. (A contingência não precisa ser invariável). Um 
objeto vermelho torna-se, então, um estímulo discriminativo, uma "ocasião" para a emissão bem sucedida da resposta "vermelho". Este esquema pressupõe que o estímulo age tanto sobre o falante, como sobre a comunidade que reforça; se não for assim, a contingência adequada não pode ser mantida pela comunidade. Mas esta condição não está presente em muitos casos de termos "subjetivos", que parecem ser respostas a estímulos privados. O problema dos termos subjetivos não coincide exatamente com o dos estímulos privados, mas há uma estreita conexão. Precisamos conhecer as características das respostas verbais aos estímulos privados, a fim de tratar da análise operacional do termo subjetivo. (Skinner 1945/1961, p.275)

De acordo com a visão de Skinner (1984), o conceito de eventos privados permitiria "estender os termos e princípios eficazes encontrados [em análises de laboratório] para a interpretação dos comportamentos onde as condições de laboratório são impossíveis" (p. 578). Outro aspecto importante, ressaltado pelo autor em diversos momentos de sua obra (Skinner, 1945/ $1961 ; 1953 / 1965 ; 1969 ; 1971)$, é que a distinção entre eventos públicos e eventos privados refere-se à acessibilidade a eles, e não a qualquer diferença de estrutura ou natureza:

A resposta "Meu dente dói” está parcialmente sob controle de uma situação à qual apenas o falante é capaz de reagir, uma vez que ninguém mais pode estabelecer a conexão necessária com o dente em questão. Não há nada misterioso ou metafísico sobre isto; o fato simples é que cada falante possui um pequeno, mas importante, mundo privado de estímulos. Até onde sabemos, suas reações a tais estímulos são bastante semelhantes a suas reações aos eventos externos. (Skinner, 1945/1961, p. 275)

Entretanto, apesar de "simples", esta diferença de acessibilidade é indicada como fonte de problemas a serem resolvidos pela análise do comportamento para um tratamento satisfatório dos eventos privados e dos fenômenos subjetivos ${ }^{4}$. A primeira dificuldade apontada por Skinner (1945/1961) seria a impossibilidade de indicar claramente o estímulo controlador envolvido. Para o autor (Skinner, 1945/1961), tal problema poderia ser resolvido a partir de técnicas de investigação fisiológica mais avançadas, que permitiriam identificar condições "dentro do indivíduo" que controlam respostas públicas referentes a estas condições. Isso possibilitaria a previsão e controle desses eventos, de modo semelhante aos casos em que os estímulos são externos (públicos). Porém, ressalta que:

[...] o problema da privacidade não pode ser completamente solucionado por uma invasão instrumental. Não importa quão claramente tais eventos internos possam ser expostos no laboratório, permanece o fato de que, no episódio verbal normal, eles são basicamente privados. Não conseguimos solucionar o segundo problema: como a comunidade consegue produzir a contingência de reforçamento necessária. Como a resposta "dor de dente" é reforçada apropriadamente, se o agente reforçador não tem contato com o dente? Não se questiona, é claro, se respostas a estímulos privados são possíveis. Elas ocorrem com bastante frequência e precisam ser explicadas. Mas por que elas ocorrem, qual é sua relação com os estímulos controladores, e quais são, se de fato existem, as características que as distinguem? (Skinner, 1945/1961, p. 276)

Skinner (1945/1961) encaminha a solução dessas questões através do comportamento verbal - uma comunidade verbal ensina a discriminação desses eventos, sendo isso possível através de quatro estratégias indiretas. Essas estratégias, brevemente descritas a seguir, explicariam os fenômenos subjetivos através dos eventos privados.

- Estímulos públicos que acompanham o estímulo privado. Exemplo: bochecha inchada acompanhando uma dor de dente.

- Respostas públicas colaterais ao evento privado. Exemplo: mancar, colocar a mão sobre a bochecha, indicando dor (na perna ou no dente, respectivamente); ficar olhando fixamente para um ponto, como indicativo de estar "concentrado" ou "pensativo".

- Respostas sob controle de estímulos privados (interoceptivos e proprioceptivos) aprendidas inicialmente a partir de eventos públicos (estímulos exteroceptivos) concomitantes. Exemplo: descrever o próprio comportamento no escuro.

- Generalização de respostas a estímulos públicos para estímulos privados. Exemplo: estímulos com propriedades coincidentes, como nas metá- 
foras: dor pontiaguda, formigamento, sentir-se deprimido ou pressionado.

Desde a proposição inicial feita por Skinner (1945/1961), o termo evento privado foi usado pelo próprio autor (e tem sido usado por analistas do comportamento em geral) para referir-se a sentimentos, pensamentos, emoções, cognições e outros fenômenos psicológicos tratados sob o rótulo de fenômenos subjetivos. Assim, a análise skinneriana sobre os eventos privados foi sendo ampliada e diversificada ao longo de sua obra (Skinner, 1957; 1953/1965; 1968; 1969; 1974/ 1976; 1989/1991). Tratando-se de tantos e tão diversos temas sob a mesma égide, é possível identificar algumas variações e até mesmo incongruências na referência a esse conceito quando trata de um ou de outro fenômeno. É nesse ponto que se à teoria de eventos privados para a análise dos fenômenos subjetivos.

\section{OUTRAS ABORDAGENS À SUBJETIVIDADE NA OBRA SKINNERIANA}

De acordo Lopes (2006) e Lopes e Abib (2003), uma análise mais cuidadosa mostra que em alguns momentos, textos skinnerianos que tratam de temas tradicionalmente identificados à subjetividade (Skinner, 1953/1965; 1968; 1969; 1974/1976), o fazem praticamente sem referência a eventos privados. Alguns exemplos nesse sentido seriam as abordagens propostas para o "pensamento" considerando o verbo pensar como comportar-se fracamente, ou ainda, como comportamento em nível encoberto (e.g., Skinner, 1953/1965; 1974/1976); ou para "emoções" e "motivação", tratadas como conceitos disposicionais (e.g., Skinner, 1945/1961; 1953/1965). Com base nisso, Lopes (2006) questiona qual a utilidade da teoria de eventos privados para o behaviorismo radical, se no momento em que deveria ser de extrema importância - na análise de fenômenos subjetivos - ela pode não ser sequer mencionada?

Além disso, segundo Lopes (2006), seria possível identificar uma diferença de tratamento conferida à teoria de eventos privados na obra skinneriana. Dois momentos poderiam ser apontados como indicativos dessa distinção: o livro Science and Human Behavior (Skinner, 1953/1965), no qual a teoria de eventos privados aparece quase como um adendo, um capítulo sem importância que "poderia ser pulado sem muitos prejuízos" (Skinner, 1953/1965, p. 258); e o livro About Behaviorism (Skinner, 1974/1976), em que a teoria de eventos privados aparece implicada na abordagem de muitos assuntos.

Questionamentos como esses apontados por Lopes (2006) convidam a uma análise do tratamento dado por Skinner aos fenômenos subjetivos. Nesse sentido, apresentam-se a seguir breves indicações e interpretações das proposições de Skinner acerca de emoções, sentimentos (feelings), pensamento, consciência e o eu (self).

\section{Emoções}

Os tratamentos dispensados a emoções e sentimentos no texto skinneriano por vezes se misturam e se confundem. Algumas vezes parecem ser sinônimos ou tratar de eventos muito próximos. Em outros momentos parecem referir-se a instâncias distintas, de maior ou menor complexidade, alternando entre, de um lado, uma condição corporal, como nas referências a respostas emocionais (enquanto padrões de respostas relativas à musculatura lisa e glândulas); e, de outro, como disposições, referindo-se a um conjunto de comportamentos que teriam suas probabilidades alteradas diante de determinados contextos.

Nos textos de 1945 e 1953, por exemplo, Skinner refere-se às emoções como fenômenos determinados por "múltiplos ou alternativos modos de reforçamento" (1945/1961, p.278), encaminhando uma explicação em termos de alta probabilidade e frequência para certos comportamentos e baixa probabilidade e frequência de outros de acordo com variáveis contextuais. Em uma proposta que pode ser chamada de explicação disposicional, apontada por Lopes e Abib (2003) e Lopes (2006) como próxima à proposta de Gilbert Ryle (Ryle, 1949/1980), Skinner (1953/1965) afirma: "Os nomes das assim chamadas emoções servem para classificar o comportamento em relação a várias circunstâncias que afetam sua probabilidade" (p. 162). E ainda:

Definimos uma emoção - na medida em que se quer fazê-lo - como um estado particular de força ou fraqueza de uma ou mais respostas, induzidas por qualquer uma dentre uma classe de operações[...] Métodos e práticas estão disponíveis para o levantamento dos efeitos de qualquer operação em que estivermos 
interessados, e um enunciado da relação parece não deixar nada de importante fora da explicação. (Skinner, 1953/1965, p. 166)

Em outro texto, Skinner (1989/1991) apresenta as duas possibilidades, indicando que as emoções seriam fenômenos que estariam presentes tanto como determinados padrões de respostas de glândulas e músculos, quanto como alterações nas probabilidades de ações - ambos determinados pelo histórico de relações com eventos ambientais.

\section{Sentimentos}

Em relação ao uso do termo sentimentos, em alguns momentos, encontramos análises mais próximas ao conceito de disposições, como quando Skinner (1989/1991) apresenta uma análise comportamental do amor, ansiedade e medo. Nos três exemplos, o autor procura destacar os processos comportamentais envolvidos, salientando a importância do papel do ambiente e do histórico de contingências de reforçamento.

Porém, ao contrário do que acontece com o conceito de emoção, na maior parte das obras o autor referese aos sentimentos como condições corporais, ou ainda, como a discriminação de condições corporais. Em diversos momentos Skinner salienta a importância da distinção entre o sentir e o que é sentido: sentir é um verbo que implica uma relação com estímulos discriminativos (o que é sentido). Nessa direção, o autor afirma:

Nós vemos, ouvimos e experimentamos coisas no mundo ao nosso redor, e sentimos coisas em nosso corpo. Quando nos sentimos fracos, estamos sentindo músculos fracos; quando nos sentimos cansados, estamos sentindo um corpo cansado; quando temos dor de dente, estamos sentindo um dente inflamado. (Skinner, 1985/1987, p.568)

Outra indicação marcante na obra skinneriana é de que as condições corporais seriam produtos colaterais das contingências de reforçamento (e.g., Skinner, 1989/1991). Possivelmente na tentativa de confrontar e refutar o status causal atribuído aos sentimentos, presente em diversos discursos do senso comum e proposições de outras teorias psicológicas contemporâneas, Skinner questiona e nega a importância da consideração dos sentimentos para a compreensão do comportamento humano: "Mas sentimentos [feelings] são na melhor das hipóteses acompanhamentos dos comportamentos" (Skinner, 1969, p. 257). Contudo, em obras redigidas mais ao final de sua carreira, o autor indica uma maior relevância na consideração desses eventos. Num texto de 1985, por exemplo, afirma: "Se nós assumirmos que o que é sentido são produtos colaterais das causas do comportamento, os sentimentos podem ser dicas úteis destas causas" (Skinner, 1985, p. 300).

Ainda, Skinner (1989/1991) parece reconhecer a possibilidade de participação dos sentimentos na relação comportamental como estímulos discriminativos, porém sem deixar de compreendê-los como efeitos das contingências de reforçamento: "a ansiedade torna-se então autoperpetuadora e mesmo autointensificadora" (p. 19). Nesse sentido, segundo Gongora e Abib (2001), ao analisar logicamente o modelo operante, pode-se afirmar que condições corporais podem participar do controle do comportamento ao menos como elos de cadeias comportamentais, mantendo no ambiente externo as causas iniciais do comportamento.

A partir dessas indicações, teríamos que o que é sentido são eventos no corpo (condições corporais) que seriam acessados, de maneira íntima e privilegiada pelo próprio indivíduo, por meio dos sistemas nervosos interoceptivo e proprioceptivo. Skinner afirma diversas vezes (e.g., 1969; 1989/1991; 1990) que a especificação de tais eventos caberia a análises da anatomia e, principalmente, da fisiologia. Para Skinner (e.g., 1974/1976), diferenças e dificuldades na discriminação e descrição de sentimentos seriam também explicadas pelo fato de que os sistemas empregados na discriminação das condições corporais internas (sistemas interoceptivo e proprioceptivo) teriam um potencial bastante limitado para estimulações mais sutis ou refinadas, se comparados ao sistema relativo à estimulação por "eventos no mundo" (sistema exteroceptivo).

Para além do papel dos sistemas envolvidos, Skinner $(1945 / 1961 ; 1953 / 1965 ; 1974 / 1976 ; 1969)$, contudo, indica outra questão, talvez a mais importante e também mais problemática referente aos sentimentos: explicar os processos por meio dos quais respostas discriminativas e descritivas de condições corporais tornam-se possíveis (Tourinho, 2007). O autor aponta 
que as respostas a condições corporais seriam produto de um arranjo especial de contingências, por uma comunidade verbal. É justamente neste ponto que incide uma das questões críticas da teoria de eventos privados: a aquisição de respostas verbais a eventos privados seria sempre imprecisa, pois quem ensina não tem acesso direto ao que é sentido e, por isso, precisaria utilizar de processos inferenciais a partir de correlatos públicos.

\section{Pensamento}

A tônica nas referências ao pensamento na obra skinneriana é a crítica, refutação e proposição da superação das teorias pautadas em faculdades mentais ou estruturas cognitivas. Como proposta alternativa, o que é chamado de pensamento, enquanto "tomada de decisão" e "solução de problemas", refere-se a situações em que o indivíduo manipula variáveis das quais um determinado comportamento é função. Essa ação deveria ser compreendida e explicada como os demais comportamentos, ou seja, através da análise dos processos comportamentais envolvidos: "Quando um homem se controla, escolhe um curso de ação, pensa na solução de um problema, ou se esforça em aumentar o autoconhecimento, está se comportando" (Skinner, $1953 / 1965$, p. 228, ênfase do original).

Skinner (1953/1965) endossa ainda o argumento de que os casos em que esses comportamentos ocorrem de maneira encoberta deveriam ser explicados da mesma forma e pelos mesmos processos que os correlatos de nível aberto. Referindo-se especificamente ao pensamento, Skinner (1953/1965) afirma que:

Muito deste comportamento encoberto é presumivelmente semelhante na forma à manipulação aberta de lápis e papel; o restante é comportamento discriminativo na forma de visão de números, letras, signos etc., o qual é semelhante ao comportamento que resultaria da manipulação aberta. (p. 273)

Nessa mesma direção, Skinner (1953/1965) afirma: "Podemos pensar antes de agir no sentido de que agimos encobertamente antes de agir abertamente, mas a ação não é uma 'expressão' da resposta encoberta ou sua consequência. As duas são atribuíveis às mesmas varáveis" (p. 279).

Skinner (1957) afirma que a regressão de uma resposta - instalada a partir de processos em nível aberto
- para o nível encoberto poderia acontecer por algumas razões, sempre referentes à relação do organismo com o ambiente: fraqueza do estímulo discriminativo (estímulos insipientes gerando respostas "fracas"); conveniência (comportamento encoberto evita que a comunidade verbal entre em contato com alguns "excessos" do comportamento do indivíduo); ou ainda, e talvez mais frequente, pelo fato de que o comportamento seria punido em nível aberto. Gongora (2003) ainda sugere que o pensar, na sua forma encoberta, pode dever-se ao interesse (a fala encoberta apresenta maior interesse ao próprio falante do que a outros ouvintes), à audiência (frequentemente a própria pessoa é a melhor audiência de si mesmo, aumentando a probabilidade do pensar ocorrer na sua forma encoberta), sua irrelevância (quando é de pouco interesse, tendo frequentemente a função de um intraverbal) e sua rapidez (permite ao falante encontrar e testar respostas rápidas evitando consequências sociais punitivas). Assim, como afirmam Lopes e Abib (2002, p. 134), "o pensamento pode ser interpretado em termos de comportamento e processos comportamentais, não importando se são públicos ou privados, pois não diferem no que diz respeito à sua natureza devendo ser tratados da mesma maneira”.

\section{Consciência}

O grande destaque dado por Skinner no estudo da consciência refere-se à consideração de sua natureza ou condição social: "Decorre, muito naturalmente, a hipótese adicional de que ser consciente, como uma forma de alguém reagir ao seu próprio comportamento, é um produto social" (Skinner, 1945/1961, p. 281).

Entendida predominantemente como um repertório autodescritivo (Skinner, 1969), a consciência seria fruto de "contingências especiais arranjadas pela comunidade verbal que fortalecem um repertório de auto-observação (introspecção) e autoconhecimento" (de Rose, 1982, p. 85). Tal repertório autodescritivo seria gerado por uma comunidade interessada em formar indivíduos capazes de fornecer descrições e elementos sobre seu próprio comportamento. Skinner (1953/1965) completa:

Desde que o indivíduo frequentemente pode observar seu próprio comportamento como um evento público, a distinção público-privado nem sempre surge. Neste caso, a acurácia do repertório autodescritivo 
pode ser adequada. [...] Mas parte da estimulação que o indivíduo recebe de seu próprio comportamento é diferente da que está ao alcance da comunidade. (p. 262)

Com isso, Skinner (1953/1965) argumenta que, quando o objeto de conhecimento passa a ser algum evento no indivíduo, como nos casos relativos à consciência, enfrentaríamos os problemas da privacidade. Teríamos, como decorrência, indicações sobre como são estabelecidos repertórios relativos a descrições de comportamentos discriminativos em relação a estímulos específicos, a partir das estratégias disponíveis para a comunidade verbal arranjar tais contingências. Aqui, como na abordagem dos sentimentos, vemos mais claramente a referência à teoria de eventos privados.

Ainda nesse tema, Skinner (1953/1965, 1969, 1974/1976) reafirma sua posição de que a consciência de determinados comportamentos pode estar envolvida na determinação de outros, mas como mais uma variável, e não como agente causador. De forma mais direta, poderíamos dizer que, para o autor, em sua "essência" o comportamento seria inconsciente. Dessa forma, consciência se trata de um repertório de discriminação e descrição de determinados comportamentos por parte do indivíduo, que pode (ou não) ser desenvolvido a partir de contingências especialmente arranjadas e estabelecidas por uma comunidade verbal.

\section{Self (o eu)}

Em um capítulo do livro Science and Human Behavior dedicado ao"Self”, Skinner afirma que o que é comumente chamado de "eu" refere-se a uma (aparente) unidade, ou algumas unidades, dentre os sistemas de respostas apresentados por um indivíduo. Já no texto “O eu iniciador", Skinner (1989/1991) reitera críticas a concepções personalistas e do eu como agente originador, mas revoga a indicação da definição do que seria o eu apresentada em obras anteriores (e.g., 1953/1965, 1974/1976), e apresenta novas considerações.

Skinner inicia o texto de 1989 afirmando que a análise científica em diversas áreas promoveu a destituição de entidades originadoras, como deuses, espíritos e essências. A análise do comportamento faria o mesmo em relação à mente ou a um eu iniciador dos comportamentos, por meio da análise das ações humanas como produtos de três níveis de seleção - filogênese, condicionamento operante e cultura. Os termos referentes ao comportamento mudariam de acordo com o nível analisado: o organismo, definido como um "corpo que se comporta" (p.44), seria o produto da seleção natural; a pessoa, enquanto repertórios de comportamentos, seria produto de processos de condicionamento operante; e o eu seria o produto de contingências culturais.

Discutindo a definição para o conceito de pessoa, Skinner (1989/1991) indica que este se aproxima da noção de persona - máscara utilizada no teatro grego. Nesse setido, argumenta que um organismo, partindo de suas possibilidades e repertórios propiciados pela seleção filogenética da espécie, desenvolveria diferentes repertórios a partir das contingências de reforçamento operante, sendo que diferentes contingências produziriam distintos repertórios para uma mesma pessoa. Isso era o que Skinner (1953/1965; 1974/1976) chamava de eu; porém, passa a indicar uma distinção entre estes dois termos (pessoa e eu): o anteriormente (1953/1965; 1974/1976) chamado de eu, agora (1989/ 1991) pessoa, são repertórios que podem ser observados por outras pessoas; já "o eu, como uma predisposição que acompanha estados internos, é observado somente através dos sentimentos ou da introspecção [...] O eu é o que a pessoa sente a respeito de si própria” (Skinner, 1989/1991, p. 45).

Tal distinção parece ser feita ainda sem muita precisão, talvez por pautar-se na distinção entre o que é observado somente pelo próprio indivíduo. Considerando as afirmações a respeito das possibilidades de conhecimento dos sentimentos, isto não implicaria que o eu seria sempre conhecido imprecisamente? Ainda, se o eu são condições introspectivamente observados, quem observa o eu? Uma pessoa (repertório)? Ou teríamos, como no tratamento anterior, de 1953, um eu-observador e um eu-observado?

Se seguíssemos o exemplo apresentado por Skinner (1989/1991), ao indicar a exortação "Conhece-te a ti mesmo", o eu seriam as condições corporais que discriminaríamos e descreveríamos. Porém, além da questão de quem conhece essas condições, tal exortação parece incluir o exame de padrões de comportamentos, ou seja, repertórios, que segundo a definição de Skinner seriam referentes à pessoa. 
Outro aspecto relevante referente ao eu apontado por Skinner (1989/1991) é que "somente sob tipos especiais de contingências verbais é que nós respondemos a certos aspectos do nosso corpo" (p. 45). É nesse sentido que o eu é fruto da seleção de práticas culturais.

Após um breve resumo dos diferentes "eus dos quais as pessoas frequentemente falam" (Skinner, 1989/1991, p. 50), o autor afirma: "Relacionamos estes eus com as contingências de reforçamento responsáveis pelo comportamento e pelas condições corporais que o acompanham e também com as contingências verbais necessariamente responsáveis por observação, estima, confiança, responsabilidade e racionalidade" (p. 51).

Nota-se por esse encaminhamento e afirmações que mesmo com avanços da fisiologia e neurologia, o que estas disciplinas observariam seriam "produtos de contingências especificáveis de variação e seleção" (Skinner, 1989/1991, p. 51). Fica claro, nesse sentido, que o interesse da proposta skinneriana é pela especificação das contingências; são elas que determinam o comportamento e o que é sentido, tanto para quem sente quanto para quem observa ou ensina a discriminação e descrição. A centralidade na explicação do eu, ou dos "eus", enquanto condições corporais, é colocada nas contingências e processos comportamentais, mais do que na distinção destes como eventos públicos ou privados.

\section{CONSIDERAÇÕES FINAIS}

A partir da análise conduzida, algumas considerações e interpretações parecem pertinentes. A afirmação de Skinner (1945/1961) sobre a relação entre eventos privados e subjetividade é um mote interessante para representar tal discussão: "O problema dos termos subjetivos não coincide exatamente com o dos estímulos privados, mas há uma estreita conexão. Precisamos conhecer as características das respostas verbais aos estímulos privados, a fim de tratar da análise operacional do termo subjetivo" (p. 275). Conforme visto nas análises apresentadas, o uso da teoria de eventos privados parece concentrar-se no tratamento de questões relativas ao conhecimento dos fenômenos subjetivos, próprios (como na consciência) e dos outros (como no tratamento de questões referentes aos sentimentos). Dessa forma, a "estreita conexão" entre a subjetividade e os eventos privados, se daria especialmente na construção de respostas verbais a estímulos privados. Nessa perspectiva, os fenômenos subjetivos poderiam ser explicados considerando-se as relações funcionais entre eventos públicos e privados e o comportamento verbal. O conceito e teoria de eventos privados seriam, portanto, um importante avanço teórico construído na obra de Skinner e demais pesquisadores da análise do comportamento.

Porém, a indicação de que "O problema dos termos subjetivos não coincide exatamente com o dos estímulos privados" (Skinner, 1945/1961, p. 275) abre espaço para argumentos como o apresentado por Lopes e Abib (2003) e Lopes (2006), de que a abordagem dos fenômenos subjetivos pode ser feita sem alusão à teoria de eventos privados, como no caso da análise apresentada sobre o pensamento. Essa proposta, alternativa considera que a proposição e defesa do conceito e teoria de eventos privados, inicialmente concebidos como um apêndice à explicação comportamental que poderia ser abandonado sem muitos problemas (Skinner, 1953/1965), desviam o foco de análise da relação comportamental, concentrando a discussão em um aspecto ou característica dicotômica (público-privado) dos eventos envolvidos nessa relação. Como apresentado, sem recorrer a eventos privados, uma explicação comportamental dos fenômenos subjetivos desenvolver-seia a partir de considerações sobre a magnitude de respostas, níveis do comportamento (aberto e encoberto) e explicações disposicionais.

Qual interpretação seguir? O debate permanece aberto e bastante pertinente, como demonstram edições recentes dedicadas ao tema em periódicos importantes da área (e.g., The Behavior Analyst, 34, 2011; Behavior and Philosophy, 37, 2009). As discussões encaminham questões teóricas, metodológicas e práticas a filósofos e cientistas do comportamento. Para muito além de impossibilitar ou encerrar os questionamentos e discussões, dizer que algo é "muito subjetivo", ao menos em uma perspectiva behaviorista radical, inaugura a trilha para muitas (e complexas) indagações.

\section{REFERÊNCIAS}

Abib, J. A. D. (1997). Teorias do comportamento e subjetividade na psicologia. São Carlos: Editora da UFSCar.

Baum, W. M. (1994). Understanding behaviorism. New York: HarperCollins College Publishers. 
Carrara, K. (2005). Behaviorismo radical: Crítica e metacrítica. São Paulo: Editora UNESP.

Carvalho Neto, M. B. (2002). Análise do comportamento: Behaviorismo radical, análise experimental do comportamento e análise aplicada do comportamento. Interação em Psicologia, 6, 13-18.

Chiesa, M. (1994). Radical behaviorism: The philosophy and the science. Boston: AuthorsCooperative.

de Rose, J. C. C. (1982). Consciência e propósito no behaviorismo radical. In B. Prado Junior (Ed.), Filosofia e Comportamento (pp. 67-91). São Paulo: Brasiliense.

Gongora, M. A. N. (2003). Itinerário para analisar comportamento verbal encoberto. In M. Z. Brandão (Org.), Sobre comportamento e cognição (Vol. 11, pp. 66-81). Santo André: ESETec Editores Associados.

Gongora, M. A. N., \& Abib, J. A. D. (2001). Questões referentes à causalidade e eventos privados no behaviorismo radical. Revista Brasileira de Terapia Comportamental e Cognitiva, 3 (1), 9-24.

Laurenti, C. (2004). Hume, Mach e Skinner: A explicação do comportamento. (Dissertação de mestrado). Universidade Federal de São Carlos, São Carlos.

Laurenti, C. (2009). Determinismo, indeterminismo $e$ behaviorismo radical. (Tese de doutorado). Universidade Federal de São Carlos, São Carlos.

Laurenti, C., \& Abib, J. A. D. (2005). Instrumentalismo científico e o modelo de seleção por consequência. In $\mathrm{H}$. J. Guilhardi \& N. C. de Aguirre (Orgs.), Sobre Comportamento e Cognição (Vol. 15,pp. 147-156). Santo André: ESETec.

Lopes, C. E. (2006). Behaviorismo e subjetividade. (Tese de doutorado). Universidade Federal de São Carlos, São Carlos.

Lopes, C. E., \& Abib, J. A. D. (2002). Teoria da percepção no behaviorismo radical. Psicologia: Teoria e Pesquisa, 18(2), 129-137. doi:10.1590/S0102-37722002000200003

Lopes, C. E., \& Abib, J. A. D. (2003). Behaviorismo radical como teoria da mente. Psicologia: Reflexão e Crítica, 16(1), 85-94. doi:10.1590/S0102-79722003000100009

Marx, M. H., \& Hillix, W. A. (1976). Sistemas e teorias em Psicologia ( $2^{\text {th }}$ ed.). (A. Cabral, Trad.). São Paulo: Cultrix.

Matos, M. A. (1995). Behaviorismo metodológico e behaviorismo radical. In B. Rangé (Org.), Psicoterapia comportamental e cognitiva: Pesquisa, prática, aplicações e problemas (pp. 27-34). Campinas: Editorial Psy.

Moore, J. (1995). Radical behaviorism and the subjectiveobjective distinction. The BehaviorAnalyst, 18, 33-49.

Pessoa Jr., O. (2010). Teoria do conhecimento e filosofia da ciência I. Classificação de posições de filosofia da ciência. [Documento em PDF]. Retirado de notas de aula em site online: http://www.fflch.usp.br/df/opessoa/ TCFC1-10-Cap11.pdf
Ryle, G. (1980). The concept of mind. New York: Penguin Books (Trabalho original publicado em 1949).

Sério, T. M. A. P. (2005). O behaviorismo radical e a psicologia como ciência. Revista Brasileira de Terapia Comportamental e Cognitiva, 7(2), 247-261.

Skinner, B. F. (1957). Verbal behavior. New York: Applenton-Century-Crofts.

Skinner, B. F. (1961). The operational analysis of psychological terms. In B. F. Skinner, Cumulative Record - Enlarged Edition (pp. 272-286). New York: AppletonCentury-Crofts. (Trabalho original publicado em 1945.)

Skinner, B. F. (1965). Science and human behavior. New York: Free Press. (Trabalho original publicado em 1953.)

Skinner, B. F. (1968). The technology of teaching. New York: Appleton-Century-Crofts.

Skinner, B. F. (1969). Contingencies of reinforcement. New York: Appleton-Century-Crofts.

Skinner, B. F. (1971). Beyond freedom and dignity. New York: Alfred A. Knopf.

Skinner, B. F. (1976). About behaviorism. New York: Vintage Books. (Trabalho original publicado em 1974).

Skinner, B. F. (1984). Coming to terms with private events. Behavioral and Brain Sciences, 7, 572-579. doi:10.1017/ S0140525X00027400

Skinner, B. F. (1985). Cognitive science and behaviourism. British Journal of Psychology, 76, 291-301. doi:10. 1111/j.2044-8295.1985.tb01953.x

Skinner, B. F. (1987). Whatever happened with psychology as a science of behavior. American Psychologist, 42(8), 780-786. doi:10.1037/00003-066X.42.8.780

Skinner, B. F.(1987). What is wrong with daily life in the western world. In B.F. Skinner, Upon Further Reflection (pp.15-31). New Jersey: Prentice-Hall. (Trabalho original publicado em 1985.)

Skinner, B. F. (1990). Can psychology be a science of mind? American Psychologist, 45, 1.206-1.210. doi:10.1037/0003-066X.45.11.1206

Skinner, B. F. (1991). Questões recentes em análise do comportamento. (A. L. Neri, Trad.). Campinas: Papirus. (Trabalho original publicado em 1989.)

Strapasson, B. A., \& Carrara, K. (2008). John B. Watson: Behaviorista metodológico? Interação em Psicologia, 12(1), 1-10.

Tourinho, E. Z. (2004). Behaviorism, interbehaviorism and the boundaries of a science of behavior. European Journal of BehaviorAnalysis, 5(1), 15-27.

Tourinho, E. Z. (2007). Conceitos científicos e "eventos privados" como resposta verbal. Interação em Psicologia, 11, 1-9.

Tourinho, E. Z. (2009). Subjetividade e relações comportamentais. São Paulo: Paradigma. 
Recebido em: 14/01/2013

Revisões requeridas em: 10/03/2014

Aceito em: 13/04/2014

\section{Notas:}

1 Referimo-nos aqui à tradição behaviorista, que abarcaria as propostas watsoniana, metodológica e radical. Críticas têm sido endereçadas indiscriminadamente a estas propostas, apesar das distinções profundas e determinantes.

2 O descritivismo científico "é uma forma de fenomenalismo empirista que busca traduzir ou reduzir os enunciados teóricos de uma teoria em termos dos enunciados de observação. [...] o descritivismo aceita que um enunciado teórico seja considerado verdadeiro ou falso, na medida em que for tradutível em enunciados de observação verdadeiros" (Pessoa Jr., 2010, p. 46-47). Segundo Laurenti (2004), Skinner baseou-se no modelo machiano de explicação do comportamento por meio da descrição de relações funcionais, entretanto, o autor incorporou em seu sistema explicativo a interpretação (no que tange o comportamento filogenético e as práticas culturais).

3 Atualmente, discute-se a impossibilidade de afirmar que um mesmo modelo de ciência foi seguido do começo ao fim da obra de Skinner. Se na década de 1930 ele é assumidamente descritivista, a partir da década de 1970 torna-se cada vez mais fácil identificar traços de um instrumentalismo (cf. Laurenti, 2004; Laurenti, 2009; Laurenti \& Abib, 2005).

4 Eventos privados podem participar de fenômenos subjetivos, mas ambos não são redutíveis reciprocamente. Os primeiros constituem-se em eventos, enquanto que os últimos constituem-se de relações entre eventos privados e públicos. 